\title{
Lead isotopes in mantle derived xenoliths from Japan and South Africa
}

\author{
MASANA MORIOKA ${ }^{1}$ and KUNIHIKo KIGOSHI ${ }^{2}$ \\ Radioisotope Centre, The University of Tokyo, Yayoi, Bunkyo-ku ${ }^{1}$ and \\ Faculty of Science, Gakushuin University, Mejiro, Toshima-ku, ${ }^{2}$ Tokyo, Japan
}

(Received February 20, 1978; accepted in revised form May 5, 1978)

\begin{abstract}
The lead isotopic compositions and the uranium, thorium and lead contents of eclogite and harzburgite inclusions from South African kimberlite-pipes and lherzolite inclusions from Itinomegata crater, Japan and of their main mineral fractions have been determined. The observed ${ }^{206} \mathrm{~Pb} /{ }^{204} \mathrm{~Pb},{ }^{207} \mathrm{~Pb} /{ }^{204} \mathrm{~Pb}$ and ${ }^{238} \mathrm{U} /{ }^{204} \mathrm{~Pb}$ in therzolite samples from Itinomegata range from 17.9 to 18.2 , from 15.1 to 15.5 and from 1.9 to 23 , respectively. The results suggest that the lherzolites were of recent crystallization.

The observed data on eclogite inclusions show no consistent pattern and suggest that they have a complicated history. The observed lead isotopic compositions of harzburgite inclusions from kimberlitepipes are ${ }^{206} \mathrm{~Pb} /{ }^{204} \mathrm{~Pb}=17.3 \sim 19.0$ and ${ }^{207} \mathrm{~Pb} /{ }^{204} \mathrm{~Pb}=15.3 \sim 15.6$. These results are distributed in a wide range on two regression lines, suggesting that they had been formed from the same source material but with different ages or have been formed recently by mixing of two different source materials and host rock of kimberlite.
\end{abstract}

\section{INTRODUCTION}

In the study of the history of differentiation process of the Earth, the isotopic composition of some elements in the mantle material is one of the important factors. Ultramafic inclusions in basalts are believed to have come from the upper mantle and are therefore often used for the study of its history. Some of the ultramafic inclusions in alkali basalts are considered, from their chemical compositions, to be representative fragments of primary upper mantle material (KUSHIRO and KUNO, 1963). On the other hand, some of the ultramafic inclusions might also be fragments of residual matter from partial melting of primary upper mantle materials (WhITE, 1966; NAGASAWA et al., 1969). However, these particular ultramafic inclusions are not necessarily representative fragments of the upper mantle but could be the residual matter from partial melting or a cumulative precipitate in magma. If the ultramafic inclusions are products of partial melting, MORIOKA and KIGOSHI (1975) suggested the possibility that the lead isotopic composition of these ultramafic inclusions might still yield information on the history of upper mantle materials, because the lead isotopic composition would not be changed by the partial extraction of lead at the event of this metamorphism. TATSUMoto (1966) and Lovering and TATSUмото (1968) discussed the uranium, thorium and lead contents and isotopic compositions of lead of volcanic rocks from Hawaii, Iwojima and Japan and eclogite inclusions in the Delegate basic pipes from Australia and in South African kimberlite-pipes, and concluded that the upper mantle is chemically heterogeneous with regard to the trace elements. ManTon and TATSumoto (1971) showed that the eclogite inclusions in kimberlite from Roberts Victor mine gave discordant ages with the different systems ( $\mathrm{Rb}-\mathrm{Sr}$, $\mathrm{U}-\mathrm{Pb}, \mathrm{Th}-\mathrm{Pb}$ and $\mathrm{Pb}-\mathrm{Pb}$ ) and pointed out that the lead of the eclogites have been contaminated with lead from the host rock of kimberlite. KRAMERS (1977) concluded that the mantle underneath southern Africa is probably different from other parts of the mantle with respect to lead isotopes and this difference is likely to have existed since more than 1.5b.y. ago.

The present paper reports the lead isotopic compositions and uranium, thorium and lead contents of some ultramafic inclusions (eclogites and harzburgites in South African kimberlitepipes, and lherzolite ejecta, Itinomegata, Japan) which might contribute to the discussion of the history of the upper mantle. 


\section{EXPERIMENTAL}

Sample preparation Each sample was sliced and divided into two parts. One portion was subjected to a bulk analysis and the other to a mineral separation. In order to obtain uniform samples free from contamination, about $50 \mathrm{~g}$ each of fresh material was taken from the interior of the original specimens. The sample for bulk analysis was washed for one minute with warm $3 \mathrm{M} \mathrm{HNO}_{3}$ to eliminate possible contamination on the surface during the slicing process, and then it was rinsed with sub-boiling distilled water and dried, and then powdered to -80 mesh in a carbon steel mortar.

The mineral separation was performed on the samples previously powdered to -80 mesh in a carbon steel mortar. Main mineral fractions were separated by an isodynamic separator and then washed for one minute with warm $3 \mathrm{M}$ $\mathrm{HNO}_{3}$ and rinsed with sub-boiling distilled water and dried.

Determination of uranium and thorium Uranium and thorium were determined by measuring ${ }^{140} \mathrm{La}$ and ${ }^{233} \mathrm{~Pa}$ produced by the following nuclear reactions:

$$
\begin{aligned}
& { }^{235} \mathrm{U}(\mathrm{n}, \mathrm{f}){ }^{140} \mathrm{Ba}-{ }^{140} \mathrm{La} \quad\left(\beta^{-}, 40.2 \mathrm{hr} .\right) \\
& { }^{232} \mathrm{Th}(\mathrm{n}, \gamma){ }^{233} \mathrm{Th}-{ }^{233} \mathrm{~Pa} \quad\left(\beta^{-}, 27.4 \mathrm{~d} .\right)
\end{aligned}
$$

About $200 \mathrm{mg}$ of the sample was weighed in a quartz vial. The sample vial was sealed and wrapped together with a reference sample. Neutron irradiation was carried out for 260 hours in the JRR-2 reactor of the Japan Atomic Energy Research Institute, at a flux of $3 \times 10^{13}$ neutrons $\cdot \mathrm{cm}^{-2} \cdot \mathrm{sec}^{-1}$. After cooling for a week, the irradiated samples were fused with $\mathrm{NaOH}$ in the presence of a known amount of ${ }^{231} \mathrm{~Pa}$ spike and barium carrier. The methods of analysis are the same as reported by WAKITA et al. (1967) but simplified by the use of a $\mathrm{Ge}(\mathrm{Li})$ solid state detector. The reproducibility of repeated runs for uranium and thorium contents determined on standards PCC-1 and AGV-1 of U.S. Geological Survey are $\pm 5 \%$ for uranium contents and $\pm 20 \%$ for thorium contents.

Determination of lead Five to ten grams of a sample was decomposed by $\mathrm{HF}$ and $\mathrm{HClO}_{4}$ in a teflon bomb at $200^{\circ} \mathrm{C}$ and dried. The residue was dissolved in hot $6 \mathrm{M} \mathrm{HCl}$ and adjusted to $2 \mathrm{M} \mathrm{HCl}$ solution. The solution was loaded in a polypropylene column containing $4 \mathrm{ml}$ Dowex $1 \times 8,100 \sim 200$ mesh anion exchange resin.
Table 1. Comparison of reproducibility for repeated runs on standard SRM-981 with accepted values of $N B S$.

\begin{tabular}{cccc}
\hline \hline Run No. & $\frac{{ }^{206} \mathrm{~Pb}}{{ }^{204} \mathrm{~Pb}}$ & $\frac{{ }^{207} \mathrm{~Pb}}{{ }^{204} \mathrm{~Pb}}$ & $\frac{{ }^{208} \mathrm{~Pb}}{{ }^{204} \mathrm{~Pb}}$ \\
\hline 1 & $16.98 \pm 0.07$ & $15.59 \pm 0.07$ & $36.90 \pm 0.20$ \\
2 & $16.91 \pm 0.08$ & $15.45 \pm 0.10$ & $36.58 \pm 0.28$ \\
3 & $17.03 \pm 0.06$ & $15.54 \pm 0.05$ & $36.68 \pm 0.15$ \\
4 & $16.90 \pm 0.03$ & $15.43 \pm 0.03$ & $36.55 \pm 0.08$ \\
5 & $16.92 \pm 0.06$ & $15.45 \pm 0.07$ & $36.55 \pm 0.15$ \\
6 & $16.95 \pm 0.08$ & $15.55 \pm 0.10$ & $36.91 \pm 0.33$ \\
7 & $16.98 \pm 0.06$ & $15.51 \pm 0.08$ & $36.75 \pm 0.22$ \\
8 & $16.95 \pm 0.04$ & $15.58 \pm 0.04$ & $36.76 \pm 0.14$ \\
9 & $16.93 \pm 0.04$ & $15.49 \pm 0.05$ & $36.58 \pm 0.15$ \\
10 & $16.91 \pm 0.04$ & $15.51 \pm 0.04$ & $36.71 \pm 0.11$ \\
\hline NBS. accepted values (10) & & \\
\multicolumn{5}{r}{} \\
\hline
\end{tabular}

Errors are based on standard deviation.

The lead fraction was eluted from the column with $6 \mathrm{M} \mathrm{HCl}$ and evaporated to dryness and electrodeposited on a platinum anode from dilute $\mathrm{HNO}_{3}$ solution (BARNES et al., 1973; MüLLER, 1938). All acids and water were distilled by means of a sub-boiling system (MATTINSON,1972) from commercial ultra-pure reagents and redistilled water, respectively. Mass spectrometric measurements were carried out using the silica gel technique (CAMERON et al., 1969) on an AEI MS-5 mass spectrometer at the Institute for Solid State Physics, The Univ. of Tokyo.

For the analysis of lead the mass discrimination caused by the use of an electron multiplier was corrected by a square root mass ratio. The lead blanks contained 4 to $10 \mathrm{ng}$. per run. This level of lead contamination can be neglected in this study, because the sample used here always contained more than $1 \mu \mathrm{g}$. of lead. The isotopic fractionation of lead was monitored by replicated analysis on standard SRM-981 of the National Bureau of Standards and the results are listed in Table 1 . The variation of this isotopic fractionation seems to depend on small differences in the analytical conditions and could not provide information on correction factors since there was no systematic trend of significant variation.

\section{Results AND Discussion}

The observed lead isotopic compositions and uranium, thorium and lead contents of the lherzolite, eclogite and harzburgite inclusions and of the main minerals separated from them are listed in Table 2. The plot of ${ }^{206} \mathrm{~Pb} /{ }^{204} \mathrm{~Pb}$ 


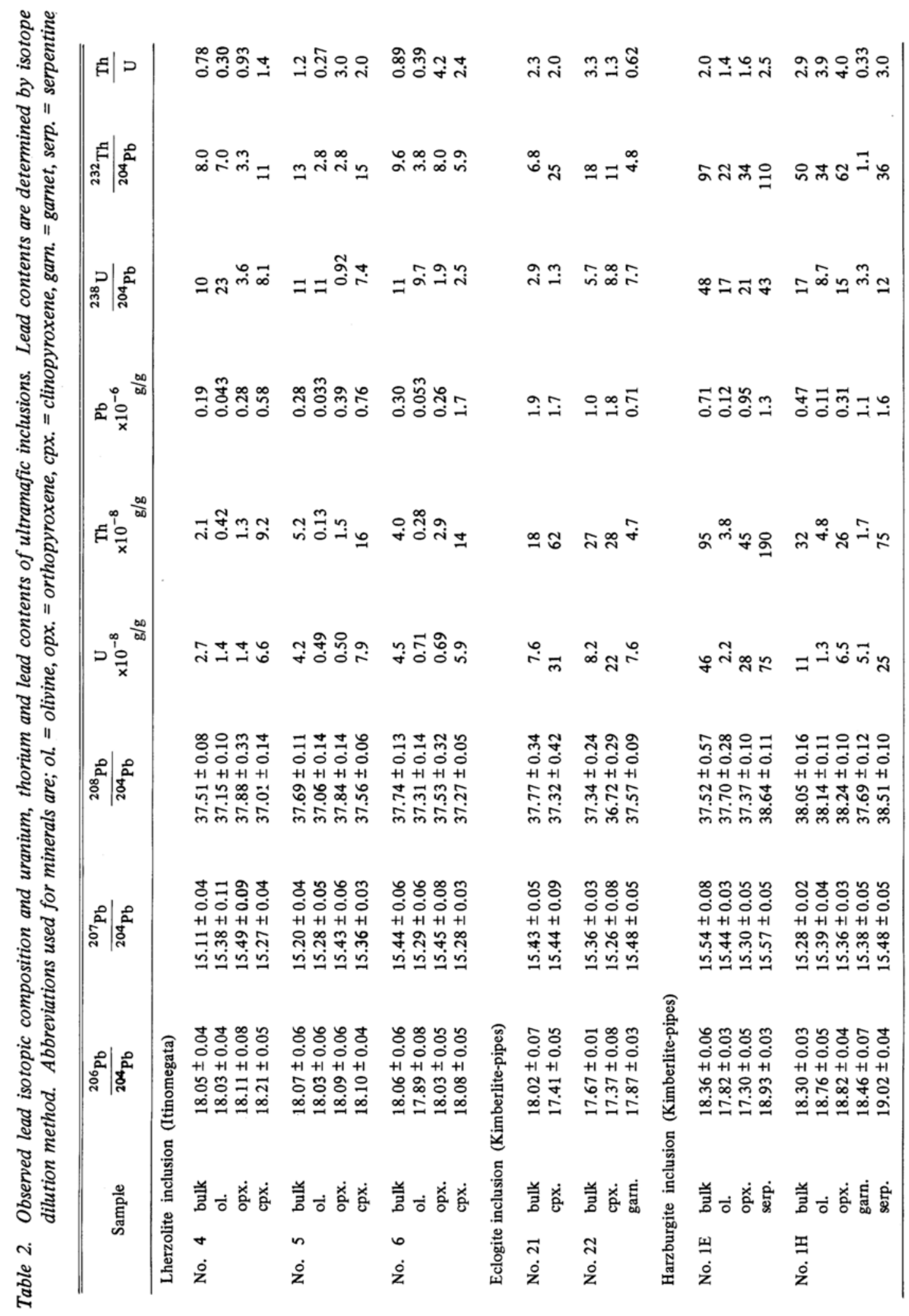




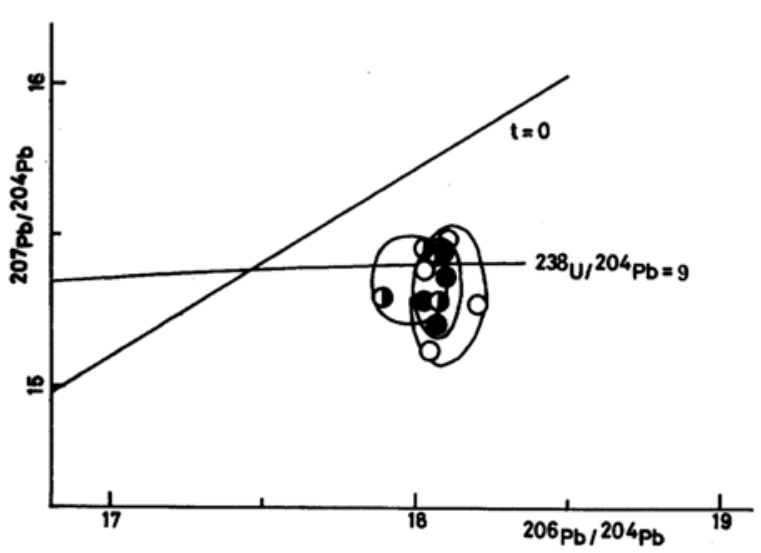

Fig. 1. ${ }^{206} \mathrm{~Pb} /{ }^{204} \mathrm{~Pb}$ versus ${ }^{207} \mathrm{~Pb} /{ }^{204} \mathrm{~Pb}$ in Itinomegata lherzolite inclusions and their mineral fractions. $\mathrm{O}=$ Sample No. 4; $\bullet=$ No. $5 ; \bullet=$ No. 6 .

versus ${ }^{207} \mathrm{~Pb} /{ }^{204} \mathrm{~Pb}$ for the ultramafic inclusions in Itinomegata and those in kimberlite-pipes are shown in Figs. 1 and 2.

As shown in Fig. 1, the lead isotopic compositions of each Itinomegata lherzolite inclusion and its mineral fractions show no easily understandable difference, although the uranium (thorium) - lead ratios vary by one order of magnitude (Table 2). The spread of the observed ${ }^{207} \mathrm{~Pb} /{ }^{204} \mathrm{~Pb}$ ratios is more than twice the deviation of the measurement on the same sample (SRM-981) as shown in Table 1. Such apparent random distributions of the ${ }^{207} \mathrm{~Pb} /{ }^{204} \mathrm{~Pb}$ ratios are expected as the results of contamination of lead from environmental water and/or host rock of samples. The samples were found as small pieces of rocks $\left(\sim 100 \mathrm{~cm}^{3}\right)$ which had been buried in pyroclastic rocks at the side wall of Itinomegata crater and came out by erosion. Although the lead in the Itinomegata lherzolite inclusions is more or less contaminated, we can conclude from the constancy of the observed ${ }^{206} \mathrm{~Pb} /{ }^{204} \mathrm{~Pb}$ that the ultramafic minerals were segregated recently from a magma, possibly the magma which produced the host basalt.

As shown in Fig. 2, the lead isotopic compositions of each eclogite and their mineral fractions could not give any definite conclusion, since there are only two and three data points, respectively, and the observed points for ${ }^{206} \mathrm{~Pb} /$ ${ }^{204} \mathrm{~Pb}$ are too close to each other to draw an isochron for each eclogite. And moreover, no consistent pattern emerges from the analytical data of the lead, uranium and thorium (Table 2). These results seem to show that the eclogite inclusions have not been in a closed system with respect to uranium, thorium and lead if

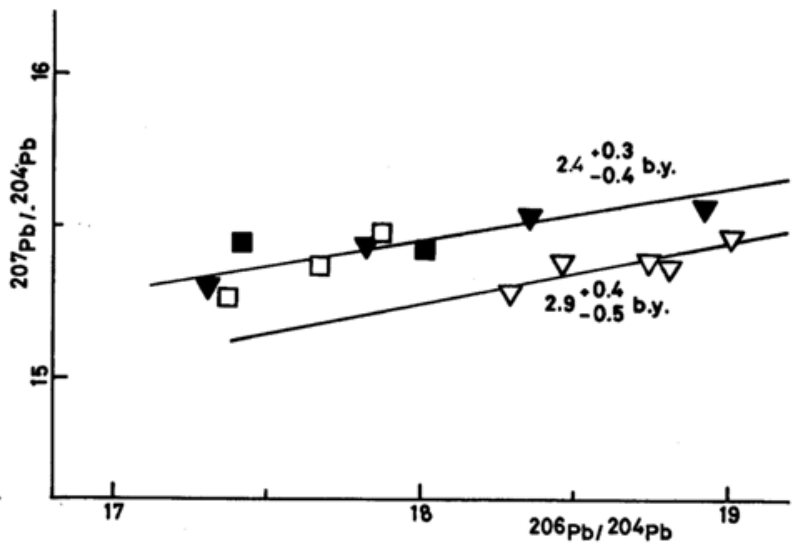

Fig. 2. ${ }^{206} \mathrm{~Pb} /{ }^{204} \mathrm{~Pb}$ versus ${ }^{207} \mathrm{~Pb} /{ }^{204} \mathrm{~Pb}$ in ultramafic inclusions and their mineral fractions from kimberlitepipes. The isochrons are for the harzburgite inclusions. The inclination of isochrons $2.4_{-0.4}^{+0.3}$ and $2.9_{-0.5}^{+0.4}$ billion years were determined from the data in this work using the weighted least square method. $=$ = Sample No. 21; $\mathrm{\square}=$ No. $22 ; \boldsymbol{\nabla}=$ No. $1 \mathrm{E} ; \nabla=\mathrm{No} .1 \mathrm{H}$.

the eclogites have old age, and are unable to offer a simple explanation. MANTON and TATSUMOTO (1971) concluded that some of the eclogite inclusions in kimberlite have undergone some degree of alteration and recrystallization with different history, comparing with the thin section examinations and the lead isotope data.

In the case of the harzburgite inclusions some of the olivines have cracks which are filled with serpentine. At the surface of the cracks there are altered fine-grained granular masses of olivine. The serpentinization does not necessarily imply the intrusion of water. Alteration of the olivine by the phlogopite is suggested by the serpentine coexisting with phlogopite fracturing into the crystal of olivine. If the alteration occurred in a closed system in the rocks two isochrons with different slopes may be drawn as shown in Fig. 2. These two isochrons suggest that there were at least two different events which formed the inclusions from the source material. The isochrons in Fig. 2 are expected to give the $\mathrm{Pb}-\mathrm{Pb}$ ages of crystallization, if the samples have been held in a closed system with resepct to uranium, thorium and lead. Assuming that the two isochrons indicate two different crystallization events from different source materials, we get $\mathrm{Pb}-\mathrm{Pb}$ ages of $2.4_{-0.4}^{+0.3}$ and $2.9_{-0.5}^{+0.4}$ billion years, respectively. These values are comparable to the mantle differentiation age of 2.8 billion years obtained by 
COOPER and RICHARDS (1966) who analyzed the data on the lead isotopic composition of volcanic rocks from various parts of the world.

In order to interpret the lead isotope data on the basis of the isochrons obtained above, we now use the two stage model which was adopted in a previous work by MORIOKA and KIGOSHI (1975). In this model, each inclusion has been held in a closed system from the time of crystallization, and also a parent material of these inclusions had been held in a closed system from 4.57 billion years ago (TАтsumoto et al., 1973) to the time of crystallization. Such a model is similar to that of ULRYCH (1967) who believed that the upper mantle existed in a closed system for the greater part of the earth's history. The growth pattern of $\mathrm{Pb}-\mathrm{Pb}$ diagram on the basis of the two stage model is shown in Fig. 3. The decay constants used for the calculation are as follows; $\lambda_{238}=1.55125 \times 10^{-10} \mathrm{y}^{-1}, \lambda_{235} \mathrm{U}=$ $9.8485 \times 10^{-10} \mathrm{y}^{-1}, \lambda_{232} \mathrm{Th}=4.9475 \times 10^{-11} \mathrm{y}^{-1}$ (JAFFEY et al., 1971; LE RouX and GLENDENIN, 1963). The lead isotopic compositions for the primary materials of these inclusions deduced from this diagram were $(13.6,14.7)$ and $(12.7$, 14.1) 2.4 and 2.9 billion years ago, respectively. The ${ }^{238} \mathrm{U}-{ }^{204} \mathrm{~Pb}$ ratio of the primary material of inclusions must have been $15 \sim 164.57$ billion years ago in order to grow up to the calculated lead isotopic compositions from primordial lead (TATsumoto et al., 1973).

The time of crystallization of the inclusions

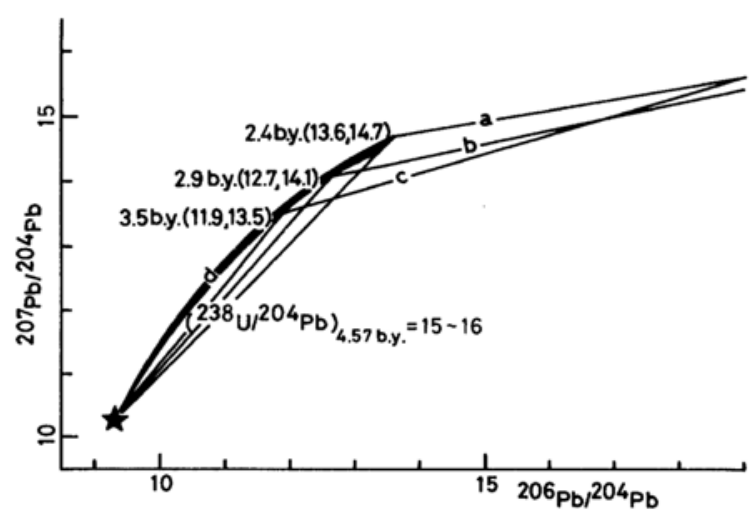

Fig. 3. Construction of two-stage model: $\star=$ primordial lead (TATSUMOTO et al., 1973); $a$ and $b=$ isochrons from Fig. 2; $c=$ isochron of Hawaiian lherzolite inclusions (MORIOKA and KIGOSHI, 1975); $d$ = first stage growth curve. $(13.6,14.7),(12.7,14.1)$ and (11.9, 13.5) are the lead isotopic composition at 2.5, 2.9 and 3.5 billion years ago, respectively. can also be calculated from the data on the lead isotopic composition and uranium, thorium and lead contents of mineral fractions from each inclusion. However, no unique internal isochron is obtained owing to the irregularly scattered values of uranium (thorium)-lead ratio in each mineral. Inconsistent results of uranium (thorium)-lead ratios support the view that the inclusions have not been preserved as a closed system with respect to uranium (thorium) or lead or both. When the inclusions have been preserved as a closed system with respect to lead, the lines in Fig. 2 may have some information on the age of crystals. When the lead in the inclusions is not preserved as a closed system, the lines in Fig. 2 suggest some regularity in the addition or subtraction of lead in the samples. The existence of secondary minerals such as serpentine supports the possibility of contamination of lead through water. It is natural to assume the addition of external water for the serpentinization in the sample, since there is no firm evidence for serpentinization by the phlogopite. If water supplied lead to the samples, the isotopic composition of lead in the water which can give the points on two straight lines shown in Fig. 2 from randomly crowded points must have high isotopic ratios such as ${ }^{206} \mathrm{~Pb} /{ }^{204} \mathrm{~Pb} \simeq 22$ and ${ }^{207} \mathrm{~Pb} /{ }^{206} \mathrm{~Pb} \simeq 16$. The existence of water containing such highly radiogenic lead is plausible, when the recoil atom effects (KIGosHI, 1971) in the process of leaching of lead are taken into consideration. And high lead content and high isotopic ratios of the lead in the serpentine compared with that in coexisting olivine support this possibility. However, the authors failed to find any relations between the amount of contaminant lead and the primary mineral species. When two straight lines in Fig. 2 are developed from two points by the addition of external lead having the same isotopic composition, it is hard to make these two points lie on the same primary growth curve.

In conclusion, the lherzolite inclusions from Itinomegata have formed recently and are contaminated with trace elements from environmental water. The analytical data of uranium, thorium and lead showed that the harzburgite inclusions from kimberlite-pipe were not preserved as a closed system with respect to uranium (thorium) or lead or both. If the inclusions were preserved as a closed system with respect to lead, the $\mathrm{Pb}-\mathrm{Pb}$ ages of these inclusions are 2.4 and 2.9 billion years, respectively. If the inclusions were not preserved as a closed 
system with respect to lead, it is possible that the contaminant lead was highly radiogenic.

Acknowledgements-We thank Drs. S. AKIMOTO and H. NAGASAWA for supplying samples for analysis and Prof. M. HONDA and the late Mr. R. GENSHO for use of the mass spectrometer at the Institute for Solid State Physics, University of Tokyo. Our thanks are due to Drs. S. BANNO, K. SATO and E. TAKAHASHI who read the manuscript and made helpful suggestions. Miss $\mathrm{T}$. HIROSE is thanked for generous assistance in the analytical work for uranium and thorium.

Appendix

Sample descriptions

No.4 6 : Lherzolite ejecta; Itinomegata crater, Akita Prefecture, Japan.

Collector: KUNIHIKo KIGOSHI.

No.21,22: Eclogite; kimberlite pipe, South Africa Locality of mine: Kimberly area

Donor: HIROSHI NAGASAWA.

No.1E : Harzburgite; Bultfontein mine kimberlite pipe, South Africa.

Mode: olivine $62 \%$, orthopyroxene $21 \%$, garnet $4 \%$, serpentine $10 \%$, phlogopite $1 \%$, carbonate $2 \%$, clinopyroxene rare.

Donor: SHUN-ICHI AKIMOTO.

No.1H : Harżburgite; Bultfontein mine kimberlite pipes, South Aftica.

Mode: olivine $63 \%$, orthopyroxene $28 \%$, garnet $4 \%$, serpentine $5 \%$, phlogopite $0.4 \%$, clinopyroxene rare.

Donor: SHUN-ICHI AKIMOTO.

\section{REFERENCES}

BARNES, I. L., MURPHY, T. J., GRAMLICH, J. W. and SHIELDS, W. R. (1973) Lead separation by anodic deposition and isotope ratio mass spectrometry of microgram and smaller samples. Anal. Chem. 45, 1881.

Cameron, A. E., Smith, D. H. and Walker, R. L. (1969) Mass spectrometry of nanogram-size samples of lead. Anal. Chem. 41, 525.

COOPER, J. A. and RICHARDS, J. R. (1966) Lead isotopes and volcanic magmas. Earth Planet. Sci. Lett. 1, 259.

JafFey, A. H., FlynN, K. F., Glendenin, L. E., BENTLEY, W. C. and EssLing, A. M. (1971) Precision measurement of the half-lives and specific activities of $\mathrm{U}^{235}$ and $\mathrm{U}^{238}$. Phys. Rev. C. 4, 1889.
KIGOSHI, K. (1971) Alpha-recoil thorium-234: Dissolution into water and the uranium-234/uranium238 disequilibrium in nature. Science 173, 47.

KRAMERS, J. D. (1977) Lead and strontium isotopes in Cretaceous kimberlites and mantle-derived xenoliths from southern Africa. Earth and Planet. Sci. Lett. 34, 419.

KUSHIRO, I. and KUNO, H. (1963) Origin of primary basalt magmas and classification of basaltic rocks. $J$. Petrol. 4, 75.

LE RouX, L. J. and Glendenin, L. E. (1963) Halflife of ${ }^{232}$ Th. Proc. Nat. Mtg. on Nucl. Energy, Pretoria, South Africa, 78.

LOVERING, J. F. and TATsumoto, M. (1968) Lead isotopes and the origin of granulite and eclogite inclusions in deep-seated pipes. Earth Planet. Sci. Lett. 4, 350.

Manton, W. I. and Tatsumoto, M. (1971) Some $\mathrm{Pb}$ and $\mathrm{Sr}$ isotopic measurements on eclogites from the Robert Victor mine, South Africa. Earth Planet. Sci. Lett. 20, 217.

MATTinson, J. M. (1972) Preparation of hydrochloric, and nitric acids at ultralow lead levels. Anal. Chem. 44, 1715.

MoRIOKA, M. and KIGOSHI, K. (1975) Lead isotopes and age of Hawaiian lherzolite nodules. Earth Planet. Sci. Lett. 25, 116.

MÜLlER, H. (1938) Neue über die Mikro-Verfahren zur Bleibestimmung mittels Elektrolyse und Dithizon. Ztschrft. f. anal. Chem. 113, 161.

NagaSaWa, H., WaKiTA, H., HiguChI, H. and ONUMA, N. (1969) Rare earth in peridotite nodules: An explanation of the genetic relationship between basalt and peridotite nodules. Earth Planet. Sci. Lett. 5, 377.

TATSUMOTO, M. (1966) Isotopic composition of lead in volcanic rocks from Hawaii, Iwo Jima and Japan. J. Geophys. Res. 71, 1721.

TATSumoto, M., KNight, R. J. and Allegre, C. J. (1973) Time differences in the formation of meteorites as determined from the ratio of lead-207 to lead-206. Science 180, 1279.

ULRYCH, T. J. (1967) Oceanic basalt leads: A new interpretation and an independent age for the earth. Science 158, 252.

WAKITA, H., NAGASAwa, H., Uyeda, S. and Kuno, H. (1967) Uranium, thorium and potassium contents of possible mantle materials. Geochem. J. 1, 183.

WHITE, R. W. (1966) Ultramafic inclusions in basaltic rocks from Hawaii. Contrib. Mineral. Petrol. 12, 245. 